
wordbook of 30,000 words. New York: Bureau of Publications, Teacher's College, Columbia University. 1944.

\section{The influence of texture density gradients on judgments of length*}

\author{
COLIN V. NEWMAN \\ University of Birmingham, Birmingham, England
}

Adult Ss judged the relative lengths of pairs of surfaces viewed successively under restricted monocular conditions. Artificial deformations in the gradients of texture density derived from one surface in each pair had a significant influence on judged length. Surfaces on which the packing density of the texture units progressively increased toward the horizon were judged as longer than surfaces of equal physical dimensions but with evenly spaced texture elements.

In his theory of visual space perception, Gibson (1950, 1959) emphasizes the importance of texture density gradients of stimulation as potential sources of information about depth. Though certain aspects of Gibson's psychophysical hypothesis have been frequently investigated, few experiments have considered the influence of texture variables on judgments of distance within a three-dimensional spatial environment. This short experiment investigates the influence of texture on judgments of the total distance to a single point on a surface, in this case, the visual horizon. Gibson (1959) argues that the specific distance of any single point on a surface is given by the stimulation gradients of disparity and motility at that point, as well as by the degree of density at that point in the textural array relative to the whole gradient of texture density which starts with the image of the nose in the field of view and ends at the visual horizon. The hypothesis to be tested is that variation in the gradients of texture density derived from a surface of constant physical dimensions will influence judgments of its length.

\section{APPARATUS}

Four test surfaces were prepared with different textures. All were $7 \mathrm{ft} 6$ in. $x 2 \mathrm{ft} 6$ in. and were painted crosswise to the line of vision with alternating black and white stripes. On the large regular textured (LRT) and the small

\footnotetext{
* The experiment reported here was one of a series conducted at the University of Leicester, England, where the author held a Social Science Research Council studentship.
}

regular textured (SRT) surfaces, all stripes were equal in width along the length of the surface. Stripes on the LRT surface were $2.0 \mathrm{in}$. wide and on the SRT surface, 1.43 in. wide. There was a progressive increase in the packing density of the stripes which thus progressively became narrower in width from one end of the surface to the other on the slowly decreasing textured (SDT) surface and to a greater extent on the fast decreasing textured (FDT) surface.

Two surfaces at a time were placed horizontally, side by side, on apparatus that permitted Ss to view them lengthwise from one end through a monocular eye-hole in a viewing box. This carried a reduction screen with two apertures. Through these apertures Ss viewed, in turn, the center portion and ends, but not the sides, of both surfaces. Vision beyond the ends of both surfaces was restricted by a white screen, mounted vertically. The FDT and SDT surfaces were placed on the apparatus framework with their wider stripes nearer to the Ss' viewing position.

\section{NOTE}

1. Mr. Steve MacKay of the University of Vichigan suggested this explanation.
The eye-hole was $1 \mathrm{ft}$ above the level of the surfaces. When the FDT and SDT surfaces were viewed at this oblique angle, they provided artificially deformed texture density gradients that corresponded to gradients from longer surfaces with texture elements of equal size throughout. It can thus be predicted that Ss will judge the relative lengths of the surfaces as follows: FDT $>$ SDT $>$ LRT $=$ SRT .

PROCEDURE

Forty-eight adult Ss of both sexes were assigned at random to one of three experimental groups with $16 \mathrm{Ss}$ in each. Each S compared the lengths of only two surfaces before proceeding to a different experiment. Ss in the three experimental groups viewed the following surfaces: Group 1, LRT and FDT; Group 2, SRT and FDT; and Group 3, SRT and SDT.

When each $S$ had been familiarized with the testing procedure, the two apertures in the reduction screen were opened in turn, permitting Ss to view both surfaces successively for $3 \mathrm{sec}$ each. Ss were required to estimate the total length of each surface separately and then report which surface they judged to be physically longer.

\section{RESULTS}

The number of Ss in each experimental group reporting each surface as longer is shown in Table 1.

Responses of "same length" were initially ignored, and the distribution of responses between the two surfaces in each group compared against equal probability using the binomial expansion. Secondly, in the stronger test with the binomial expansion, the responses of "same length" were added to responses of "longer" on the evenly striped surfaces in each group. Results are shown in Table 1.

Informal questioning at the end of the experiment revealed that Ss had not detected any variation in the physical width of the stripes along any surface. After the experiment most Ss expresses surprise when shown that the surfaces were in fact equal in length.

Table 1

Subject's Reports as to Which Surface was Longer

\begin{tabular}{|c|c|c|c|c|c|}
\hline $\begin{array}{l}\text { Experimental } \\
\text { Group }\end{array}$ & Surface & Reported as & Longer & $\begin{array}{c}\text { Binomial } \\
\text { Test }\end{array}$ & $\begin{array}{c}\text { Stronger } \\
\text { Binomial } \\
\text { Test }\end{array}$ \\
\hline 1 & $\begin{array}{c}\text { LRT } \\
1\end{array}$ & $\begin{array}{l}\text { FDT } \\
13\end{array}$ & $\begin{array}{c}\text { Same } \\
2\end{array}$ & $\begin{array}{l}\mathrm{N}=14 \\
x=2 \\
\mathrm{p}<.001\end{array}$ & $\begin{array}{l}\mathrm{N}=16 \\
x=3 \\
\mathrm{p}<.011\end{array}$ \\
\hline 2 & $\begin{array}{c}\text { SRT } \\
2\end{array}$ & $\begin{array}{c}\text { FDT } \\
12\end{array}$ & $\begin{array}{c}\text { Same } \\
2\end{array}$ & $\begin{array}{l}\mathrm{N}=14 \\
x=2 \\
\mathrm{p}<.006\end{array}$ & $\begin{array}{l}N=16 \\
x=4 \\
p<.038\end{array}$ \\
\hline 3 & $\begin{array}{l}\text { SRT } \\
5\end{array}$ & $\begin{array}{l}\text { SDT } \\
11\end{array}$ & $\begin{array}{c}\text { Same } \\
0\end{array}$ & $\begin{array}{l}\mathrm{N}=16 \\
x=5 \\
\mathrm{p}<.105\end{array}$ & $\begin{array}{l}N=16 \\
x=5 \\
p<.105\end{array}$ \\
\hline
\end{tabular}




\section{DISCUSSION}

Variations in the texture density gradients of stimulation derived from the surfaces were found to influence judgments of their relative physical lengths. Results showed, however, that with greater differences between the comparison gradients, apparent differences in length were more frequently reported. Furthermore, some Ss made judgments out of keeping with those predicted from the information contained in the gradients. It is clear that on its own the texture density gradient does not unequivocally specify the length of the surface to all Ss. Additional stimulation gradients of disparity and motility are probably also required before exact psychophysical correspondence is possible. On its own, however, artificial deformations in the gradient of texture density from a surface can exert a significant influence on judgments of length. This finding supports Gibson's view and provides further evidence for the influence of higher order variables of stimulation on distance perception.

$$
\text { REFERENCES }
$$

GIBSON, J. J. The perception of the visual world. Boston: Houghton Miffin, 1950.

GIBSON, J. J. Perception as a function of stimulation. In S. Koch (Ed.), Psychology: $A$ study of a science. Vol.1. New York: MoGraw-Hill, 1959. Pp. 456-501. 